\title{
Application of BIM-technologies during the construction and operation of buildings and structures
}

\author{
Andrey Bogdanov ${ }^{1 *[0000-0002-0129-5942]}$, Vladislav Zaitsev ${ }^{1}$, and Karina Khalitova $^{2}$ \\ ${ }^{1}$ Kazan State University of Architecture and Engineering, 420043 Kazan, Russia \\ ${ }^{2} \mathrm{OOO}$ «Khansky dom», 105A Yamasheva Ave., 420044 Kazan, Russia
}

\begin{abstract}
The relevance of implementing BIM technologies at all stages of the building's life cycle from design to decision-making on its demolition is shown. Variants of the stress-strain state of buildings and structures are considered. An algorithm for analyzing incoming information and making decisions about major repairs, reconstruction, or demolition of an object is developed, depending on the values of parameters, their duration, and combinations obtained from sensors installed during their construction. The use of fiber-optic sensors for obtaining information and subsequent analysis of the state of the building structure and determining dangerous movements of its individual elements is proposed.
\end{abstract}

Keywords. BIM-technologies, construction complex, monitoring, quality control, technologies, construction.

\section{Introduction}

Information Modelling (BIM-technologies), provides for the construction of one or more digital models of buildings or structures. Such Modelling facilitates the design process at all its operational stages, providing more thorough control and analysis [1]. Developed BIM models of buildings are filled with information about the exact geometry of structures and all the necessary data for purchasing materials, manufacturing structures, and performing construction and installation works [2].

The problems of implementing BIM-technologies at the design stages are quite well developed. Regulatory and technical documentation has been developed along with theoretical studies [3]. The practical application of this technology at the stage of construction, the life cycle of a building in case of wear and tear, which requires modernization, reconstruction or demolition, has not been sufficiently studied and developed.

The ability to use BIM-technologies will not only save time and financial resources, improve the quality of construction and installation work, providing continuous monitoring of the current state, but also help make the construction process itself more open, safe and «transparent» [4].

*Corresponding author: gold04@mail.ru 
The most effective way to solve the problem of safety in buildings at present is the formation and implementation of automatic monitoring as part of BIM, which provides complete and continuous monitoring of the state of critical structures [5].

In this article, the goal is to determine the types of structures to be monitored, to create an algorithm for action when changes occur in emergency situations during the construction and operation of buildings and structures. To achieve this goal, it is necessary to study the typical factors that affect the deformations of buildings and structures.

\section{Materials and methods}

The research uses structural and comparative methods of analysis.

Domestic and foreign experience of using monitoring systems at various stages of the life cycle of buildings and structures is analyzed:

1 - design;

2 - construction;

3 - operation of the building, maintenance of structural elements and engineering systems of the building in normal technical condition;

$4-$ a period of physical and moral deterioration that requires modernization or reconstruction.

5 - end of life cycle period.

The list of data necessary for the automated monitoring system to collect, organize, store, and analyze the obtained data on controlled parameters is established.

The object of research is defined as a monitoring system consisting of BIM-technologies unique to critical buildings and structures.

The research method is used to construct an automated monitoring system with an optimal set of software and hardware based on BIM-technologies.

\section{Results and discussion}

Automated monitoring of load-bearing structures of buildings helps to detect negative changes in the deformation state of the building in a timely manner, which can cause destruction and death of people.

In [6], the experience of using the hardware and software parts of the monitoring system, which is used to assess the technical condition of the main load-bearing structures of two large-span sports complexes, is considered. A system of static and dynamic monitoring has been developed for continuous assessment of the current technical condition of the loadbearing structures of the surface and the subtribe space of sports facilities. As a strain sensor, a displacement sensor is used, which is based on the Hall effect. The software part includes the calculation of the stress-strain state of building structures using the ANSYS, LS-DYNA software package and the control program of the Geotek SHM monitoring system [7].

It is proposed to apply a scheme for remote monitoring and diagnostics of the state of structures and civil engineering structures, consisting of wired sensors, a controller and a dispatcher terminal [8]. Communication between the terminal and the controller is carried out either via a modem or an Ethernet network. The processed data is sent both to the dispatcher's terminal and to a special Internet site. As a result, the owner of the object, being at any point, will be able to find out its technical condition.

The development of methods for measuring strain and temperature using fiber-optic sensors and the creation of measurement systems based on them are carried out in many scientific organizations and research and production companies both in Russia and abroad [9].

The main issue when constructing a monitoring system for load-bearing structures is the choice of parameters and structural elements that are subject to automated (automatic) control. 
There can be no unambiguous answer to this question, since any supporting structure is responsible, and any design may have either a factory defect during its manufacture or defects during installation work. Monitoring absolutely all structures of an object is not cost-effective and impractical, so the main goal when developing a method for monitoring an object should be to determine the optimal composition of structural elements and control parameters that will allow the most complete assessment of the condition of structural elements of the object.

To select the optimal composition of the monitored structural elements, it is necessary to study the typical factors affecting the geometric parameters and the stress-strain state (VAT) of buildings and structures [10].

The most significant factors that can influence changes in VAT, reduced load-bearing capacity (NS) of a building, and changes in its spatial position are:

1. Uneven draught (subsidence) of the ground base, which may cause rolls of the loadbearing frame, which may change the VAT of structural elements of the load-bearing frame of the building and reduce the load-bearing capacity [11].

2. Tight construction of buildings to each other. Fig. 2 shows that the end part of the building tilts with a bend [12].

3. Weakening of the bearing capacity of soils on the slope. The example shows the deformation of a building located on an inclined underlying layer (Fig. 3). Precipitation weakens the bearing capacity of the soil, resulting in deformations of the building [11].

4. Influence of geological faults on building deformations. The study of the geological situation is extremely important in the construction of buildings [11]. Geological faults negatively affect the operation of structures and provoke the opening of cracks and possible destruction (Fig. 4).

5. Exceeding the permissible operating loads on the building. Various loads: alternating, cyclical, can cause uneven precipitation (Fig. 5a), and a strong wind or hurricane - an unacceptable roll of the entire structure. Highly varying loads that are transmitted to foundations can create significant uneven precipitation and deformations [13].
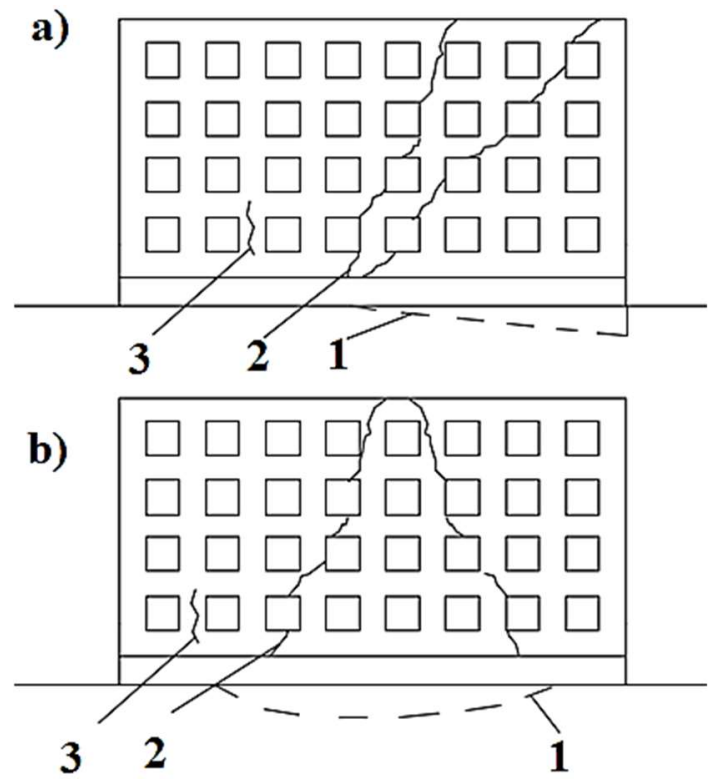

Fig. 1. Building deformation due to uneven ground precipitation (a, b): 1 - deformation line; 2 - crack due to foundation precipitation; 3 - crack due to wall overloads. 


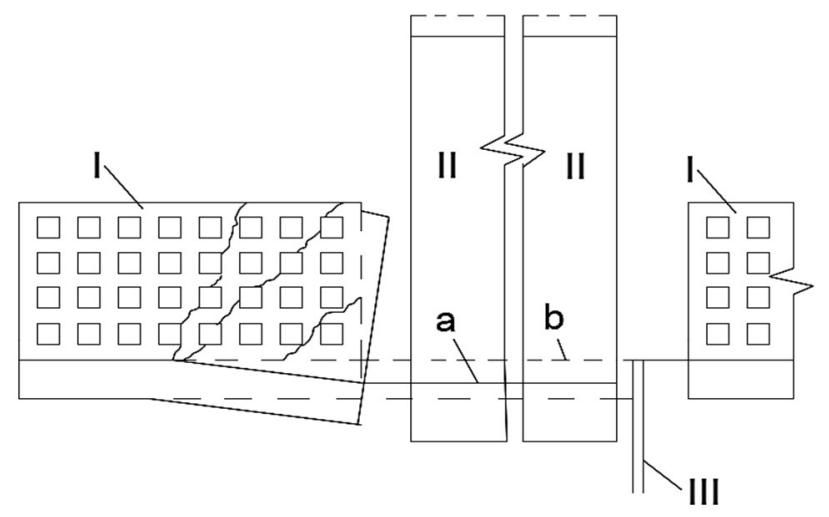

Fig. 2. Deformation of an existing building I due to dense construction of a high-rise building II: a - no measures that block the influence of dense construction of the building on the previously built building; $\mathrm{b}$ - when using measures in the form of cutting the base with a sheet pile wall III.

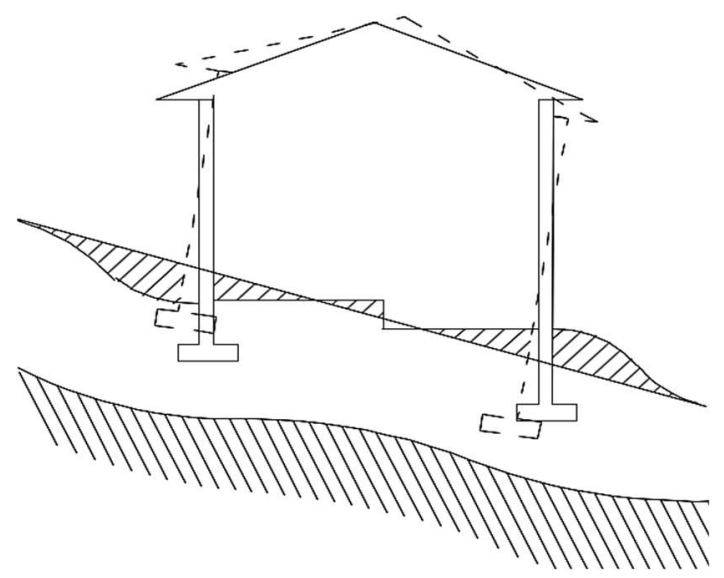

Fig. 3. Deformation of a building located on an inclined slope the underlying layer.

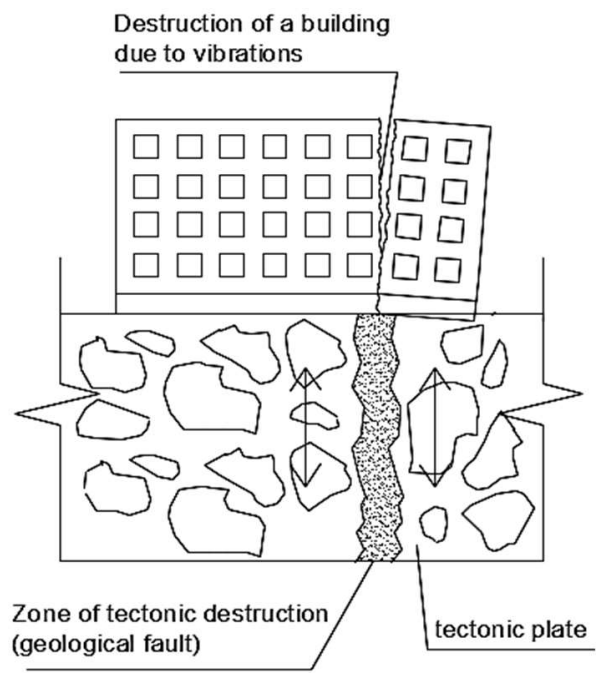

Fig. 4. Destruction of a building over a geological fault. 
a)

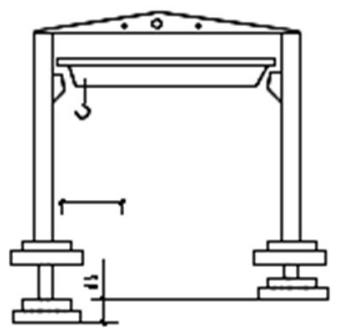

c)

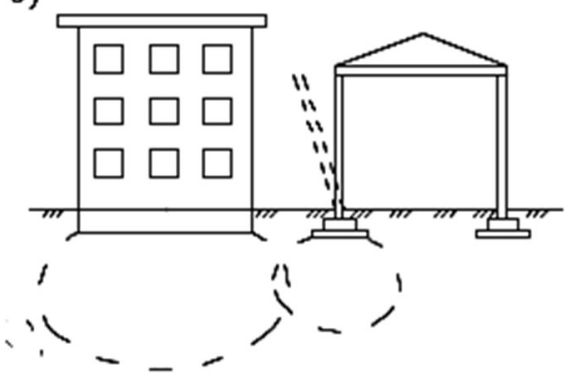

b)
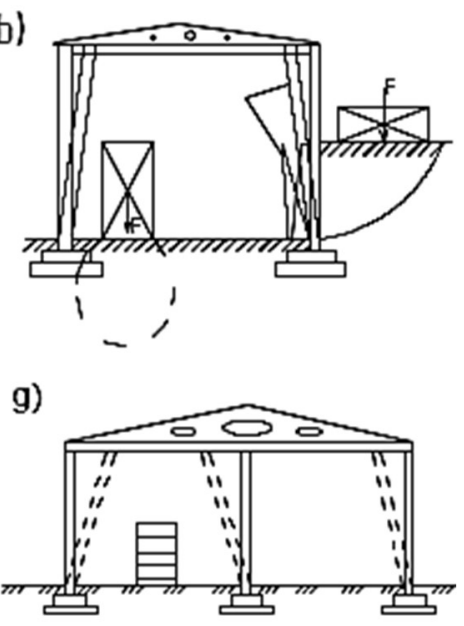

Fig. 5. Deformations of buildings caused by operating loads.

Exceeding the design load of floors creates vertical and horizontal movements of structures (Fig. 5b). It is necessary to take into account the deformations of the base, which consist in the distribution capacity of the soil, which is manifested in lowering the surface outside the loading spot, increasing the stress in the foundation base when building a new building next to it (Fig. 5c).

Technological equipment can create loads that exceed the designed ones, which leads to structural deformations (Fig. 5g).

6. Static and dynamic (pulsation) components of snow and wind loads, respectively.

Based on the analysis carried out above, the optimal composition of structures that are subject to monitoring of most objects is identified:

1. Residential and public buildings: foundations, columns, walls, pillars, pillars, floors, junctions of load-bearing structures.

2. Industrial buildings: foundations, columns, trusses and sub-trusses, crane girders, girders, junctions of load-bearing structures.

Based on the conducted research, the authors of this article developed an algorithm for actions in the event of extreme loads on structures.

\section{Conclusion}

At the construction stage of the facility, the use of technologies that minimize the use of labor and create maximum involvement of devices with remote transmission of received data will not only reduce the time required for quality control, but also the financial component. For example, the laser scanning method [14] will allow solving problems of territorial planning, help at the stages of design, construction and reconstruction, making regular audits of construction work, without the need for repeated visits to the object.

At the construction stage, the system equipment is installed (strain, pressure, temperature, vibration sensors, etc.). They will allow quality control during the construction process by using installed technical equipment, the results of which are compared with the obtained values of controlled parameters based on mathematical modeling. Thus, during construction, 
the adequacy of the mathematical model is checked and, if necessary, the rules for processing monitoring results and decision-making criteria are clarified [15].

At the stage of object operation, the given methodological principles [16] for constructing monitoring systems for unique buildings allow us to timely determine the threat model, the lack of response to which can cause deterioration of the technical condition of the structure. Based on the threat model, they determine the composition of controlled parameters, processing rules, and criteria for evaluating the object's technical condition.

Based on the monitored parameters, it is possible to determine the specific composition of the physical quantities required for measurement (deformations, vibrations, pressures, etc.) and the monitoring system equipment.

The principles of monitoring the load-bearing structures of unique buildings presented in $[17,18]$ can be taken as the basis for quality control of reinforced concrete monolithic structures. This will make it possible to determine the calculated parameters of the monitoring system control, such as the calculated deformations in the foundation plate, piles, loadbearing structures, and the calculated dynamic characteristics of the object [19]. In turn, the data transmitted to the PC will be processed, a comparative analysis of the design and construction digital models will be made, and hypotheses about the model being used will be put forward. the use of such a method approach together with the laser scanning method for the quality of construction and installation works will eliminate the possibility of critical conditions on each of the digital models, and will save you from overspending of building materials and products, for example, rebar and concrete [20].

\section{References}

1. A.N. Dmitriev, I.L. Vladimirova. Information modeling technologies in the management of construction projects in Russia, Promyshlennoe i grazhdanskoe stroitel'stvo, 48-59 (2019).

2. A.N. Dmitriev. Development of digital methods for assessing innovations of investment and construction projects to improve their energy efficiency, Industrial and civil construction, 13-20 (2018).

3. E.S. Rakhmatullina. BIM-modeling as an element of modern construction, Russian Journal of Entrepreneurship, (2017).

4. O. Stephen. On-demand monitoring of construction projects through a game-like hybrid application of BIM and machine learning, Automation in Construction, 451-459 (2020).

5. D.N. Kosykh, N.K. Sursanov. The need to use modern monitoring methods in construction, Modernizatsiya i nauchnyye issledovaniya $\mathrm{v}$ transportnom komplekse, 137-138 (2017).

6. G.G. Boldyrev, D.N. Valeev, A.A. Zhivaev, I.Kh. Idrisov. Experience of practical application of monitoring systems for building structures, In the world of non-destructive testing, 54-59 (2010).

7. X. Zhang. Automatic underground space security monitoring based on BIM, Computer Communications, 85-91 (2020)

8. A.B. Ponomarev, V.G. Ofrikhter. The need for system monitoring of operated structures in order to ensure their structural safety, Vestnik tsentralnogo regionalnogo otdeleniya Rossiyskoy akademii arkhitektury i stroitelnykh nauk, 134-139 (2016).

9. A.D. Terelyanskiy. Decision making system. Development experience, Izvestiya VolgGTU, 162-168 (2014).

10. E.Y. Golovina. Corporate information systems and methods of their development, Vestnik MEI, 94-101 (2018). 
11. V.V. Ledenev. Accidents, destruction and damage. Causes, consequences and warnings: monograph, Publishing house of the Federal State Budgetary Educational Institution of Higher Education «TSTU», (2017).

12. N.N. Posokhov, S.G. Azarov, M.Y. Proshlyakov. Problems of development of monitoring systems for potentially dangerous objects and ways to solve them, Monitoring. Nauka $\mathrm{i}$ bezopasnost, 8-11 (2017).

13. A.M. Shakhramanyan, Y.A. Kolotovichev. Experience in using automated systems for monitoring the deformation state of load-bearing structures at the Olympic facilities in Sochi-2014, Vestnik MGSU, 92-105 (2015).

14. N.N. Alekseenko. Application of laser scanning technology in various industries and at various stages of the life cycle of an object, Vestnik MGSU, 62-73 (2016).

15. A. Darko. Building information modeling (BIM)-based modular integrated construction risk management - Critical survey and future needs, Computers in Industry, 21 (2020).

16. A.I. Mukhaev, I.V. Popova, Y.V. Dedichkina. Analysis of the current state and prospects for the development of housing construction in the Russian Federation, Sovremennyye problemy nauki i obrazovaniya, 121-145 (2014).

17. D. Kuzevanov. Control of the quality of construction works based on the use of information models: collection of articles, III International Forum of High-Rise and Unique Construction 100+ Forum Russia, 8-15 (2016).

18. A.M. Shahramanyan. Methodical bases of creation of monitoring systems of load-bearing structures of unique objects, Vestnik MGSU, 256-261 (2011).

19. I.Y. Zilberova, K.S. Petrov. Problems of reconstruction of residential buildings of different construction periods, Inzhenernyy vestnik Dona, 214-229 (2012).

20. Y. Cheng. BIM integrated smart monitoring technique for building fire prevention and disaster relief, Automation in Construction, 14-30 (2017).

21. V.O. Zaitsev, A.N. Bogdanov, Izvestiya KGASU 4, (2020).

22. R.K. Mukhametrakhimov, L.V. Lukmanova. Mag. Civ. Eng. 102, 10206 (2021). DOI: 10.34910/MCE.102.6. 